\title{
La literatura en torno a las hijas de los Reyes Católicos: inicios de una tesis doctoral ${ }^{1}$
}

\author{
Ruth MARTíNEZ ALCORLO \\ Universidad Complutense de Madrid \\ rmalcorlo@filol.ucm.es
}

\section{RESUMEN}

Las infantas Isabel (1470-1498), Juana (1479-1555), María (1482-1517) y Catalina (14851536), hijas de los Reyes Católicos, son mujeres de una importancia excepcional en la política internacional llevada a cabo por sus padres. Al contrario que su hermano, el príncipe don Juan, aún carecemos de una monografía que explore en su educación y cultura, su mecenazgo en torno a las artes y, sobre todo, la literatura escrita para ellas en su entorno. El objetivo primordial de la tesis que aquí se presenta será reunir todos estos puntos. Para ello, la interdisciplinariedad y la combinación de filología e historia resultará fundamental en la construcción de discursos políticos en torno a estas mujeres, especialmente en lo relacionado con la literatura realizada con motivo de sus matrimonios, como por ejemplo el desconocido poema latino conocido como Epithalamium, escrito por Antonio de Nebrija con motivo de las bodas de la infanta Isabel y el príncipe Alfonso de Portugal.

Palabras clave: Infantas de Castilla, Reyes Católicos, interdisciplinariedad, literatura, matrimonios.

\section{ABSTRACT}

The Infantas Isabel (1470-1498), Juana (1479-1555), Maria (1482-1517) and Catalina (1485-1536), Catholic Kings' daughters, are women with an outstanding importance in the

\footnotetext{
${ }^{1}$ El presente artículo se enmarca dentro de las actividades del proyecto de investigación $\mathrm{I}+\mathrm{D}$ del Ministerio de Economía y Competitividad La actividad literaria en la época de los Reyes Católicos (ref. FFI 2008-01280/FILO) y del grupo de investigación de la Universidad Complutense de Madrid Sociedad y Literatura Hispánicas entre la Edad Media y el Renacimiento (ref. 941.032), ambos dirigidos por el doctor Nicasio Salvador Miguel, director de esta tesis, a quien agradezco la atenta revisión de este trabajo y los siempre sabios consejos para mejorarlo. Igualmente, en estos comienzos de mi investigación, me gustaría dar las gracias a quien más me animó a entrar en este maravilloso mundo, el doctor Santiago López-Ríos Moreno.
} 
international politics arena developed by their parents. In contraposition to what happens to their brother the Crown Prince Juan, we still do not have a full monograph about their education, culture, sponsorship to arts and, above all, about all the written literature about them in court. The aim of the present thesis is collecting all these aspects. The joint of interdisciplinarity and connection between Philology and History are extremely important to know more of their political discourses, specially the literature derivated of their marriages such as the unknown latin poem called Epithalamium, written by Antonio de Nebrija for Infanta Isabel's marriage with the Prince Alfonso of Portugal.

Keywords: Infantas of Castile, Catholic Kings, interdisciplinarity, literature, marriage.

Sumario: 1. Presentación y objetivos 2. Metodología 3. Hacia un esbozo de la tesis 4. Algunos problemas: el caso de Juana 5. Los inicios: el caso de Isabel 6. Conclusión

\section{Presentación y objetivos}

Con motivo del V centenario de la muerte del príncipe don Juan, hijo de los Reyes Católicos, se celebraron numerosos congresos así como vieron la luz diferentes monografías, artículos o estudios dedicados a la figura del heredero, trazando su historia, educación y literatura ${ }^{2}$. A pesar de su corta vida, el príncipe don Juan ha gozado de un interés especial por parte de la crítica que contrasta (y mucho) con la escasa atención que se ha prodigado a las hijas de los Reyes Católicos, las infantas Isabel, Juana, impropiamente llamada "la loca" por la historia, María y Catalina. Las cuatro son piezas clave dentro de la política internacional realizada por sus padres y sus vidas están necesariamente unidas a sus matrimonios de estado con los futuros monarcas de Portugal, el Imperio o Inglaterra. Aunque contamos con una gran cantidad de estudios dedicados a trazar sus biografías, novelar sus desventuras o desvelar la importancia histórica de los acontecimientos en los que se vieron envueltas, es necesario elaborar una amplia monografía que explore en su formación y cultura, su mecenazgo en torno a las artes y la literatura escrita en su entorno. Reunir todos estos aspectos, así como editar con todo rigor filológico los textos necesarios, será el objetivo primordial de mi tesis, titulada, provisionalmente: La literatura en torno a las hijas de los Reyes Católicos.

${ }^{2}$ Como muestra, el seminario titulado La literatura en tiempos del príncipe don Juan organizado por la SEMYR (enero de 1997) o el ciclo de conferencias V Centenario de la Muerte del Príncipe don Juan, organizado por el Exmo. Ayuntamiento de Ávila (octubre 1997). Véanse las monografías y artículos reseñables dentro de una ingente bibliografía entre la que destaco los trabajos de M. Á. Pérez Priego (1992) y (1997); J. Sanz Hermida y Á. Alcalá Galve (1999) y, finalmente, T. González Rolán, J. M. Baños Baños y P. Saquero SuárezSomonte (2005). 
A través de este artículo, se pretende dar a conocer las líneas fundamentales de mi investigación, así como la metodología interdisciplinar necesaria para llevarla a cabo, los posibles problemas que se puedan derivar y, por último, presentar los inicios de mi estudio al esbozar el caso de la infanta Isabel.

\section{Metodología}

Para enfrentarnos a tan ardua tarea, la interdisciplinariedad será la más valiosa de las herramientas. La combinación de filología más historia resultará, de todo punto, necesaria, pues sin la imbricación de este binomio es imposible entender la literatura de fines del siglo XV y principios del XVI. Así, también la interrelación existente entre la literatura castellana con la latina en dicho periodo renacentista hace patente la necesidad y utilidad que alberga la investigación interdisciplinar. A este respecto, el maestro Keith Whinnom, hace ya unos cuantos años, llamó la atención entre los hispanistas sobre la figura del filólogo "anfibio", para referirse a aquel que sabe moverse entre los textos clásicos y castellanos ${ }^{3}$.

Pero también será de obligado cumplimiento acudir a otras disciplinas, las mismas que se consideraron "ciencias ancilares" de la historia, pero que ayudan al investigador en su camino; me refiero, por ejemplo, a la bibliografía material. Esta disciplina tendrá suma importancia en el estudio tipobibliográfico a la hora de desentrañar ediciones y variantes textuales en una futura labor editorial; también la paleografía, pues resultará vital en el estudio de los documentos manuscritos que se conserven de mano de las infantas así como la archivística y documentación, con escritos a los que acudir de primera mano y que tracen el devenir de sus vidas y los hechos políticos en los que se involucraron y, por último, la historia del arte, pues parecen numerosos los retratos y cuadros que han tenido como fuente de inspiración a las hijas de los Reyes Católicos a lo largo del curso de la historia.

\section{Hacia un esbozo de la tesis}

Ante este planteamiento surge un vasto panorama de trabajo al esbozar el índice de la tesis. Inicialmente, habrá que trazar un contexto histórico y político de la época de los Reyes Católicos, realizando un especial hincapié en los hechos que atañen a las infantas. En este camino histórico también se muestra primordial elaborar una completa biografía de cada de ellas, puesto que, exceptuando los casos de Juana y Catalina, que han hecho correr ríos de tinta, quedan lejanos en el tiempo los desconocidos perfiles de las que podríamos denominar "infantas portuguesas", es decir, Isabel y María ${ }^{4}$.

\footnotetext{
${ }^{3}$ K. Whinnom (1994), p. 97.

${ }^{4}$ Independientemente de los datos que aparecen en las canónicas biografías y monografías sobre los Reyes Católicos de Tarsicio de Azcona, Luis Suárez o Ernest Belenguer, me refie-
} 
Una parte fundamental de mi investigación la representa la dedicada a la formación y educación recibida por las infantas. En la senda de los trabajos a los que se ha venido dedicando el profesor Salvador Miguel ${ }^{5}$, la importancia de la temprana enseñanza condicionaría la posterior cultura de estas mujeres. La reina Isabel dio a sus hijos una esmerada educación, sin distinción entre el príncipe y las infantas, pues así les dotaba de todo lo necesario para el ejercicio del buen gobierno y la justicia. Dicha instrucción, que solía comenzar sobre los siete o diez años de edad para los varones y un poco más tarde para las mujeres, era la propia para desempeñar las funciones a las que sus hijas estaban llamadas, donde destacaba el aprendizaje y dominio del latín y otras lenguas, el conocimiento de los clásicos, así como de la Biblia y otros textos. Sin descuidar, claro está, las labores femeninas propias que se dedicaban a «hilar, coser y labrar». Por tanto, la educación en el entorno de la reina Católica se centraba en tres puntales básicos: lo espiritual, lo intelectual y lo cortesano $^{6}$.

Pero es el estudio y dominio del latín lo que despierta las mayores admiraciones entre los habituales de la corte. El humanista valenciano Juan Luis Vives, en su De institutione feminae christianae (Lovaina, 1523), dedicado a la infanta Catalina, destaca que

la edad nuestra vio aquellas cuatro hijas de la reina doña Isabel [...] tener muy buenas letras. De todas partes me cuentan en esta tierra y esto con grandes loores y admiración, que la reina doña Juana, mujer del rey don Felipe [...] haber improvisado de presto en latín a los que por las ciudades y pueblos adonde iba le hablaban según es costumbre hacer los pueblos a los nuevos príncipes. Lo mismo dicen los ingleses de su reina doña Catalina de España, hermana de la dicha reina doña Juana. Lo mismo de las otras dos que murieron reinas de Portugal ${ }^{7}$.

ro a los lejanos estudios de Félix de Llanos y Torriglia (s. a.), (1944) y (1946); J. M. Cordeiro de Sousa (1951), pp. 657-696) y (1954), pp. 33-51. Más cercano es el artículo de J. Sanz Hermida (2004), pp. 379-394. En el transcurso de la celebración de las Jornadas de Iniciación a la Investigación en Literaturas Hispánicas, y gracias a la Dra. Sandra de Jesús Boto, he conocido que en Portugal se está preparando la colección "Rainhas de Portugal", coordinada por Ana Maria S.A. Rodrigues, Manuela Santos Silva e Isabel dos Guimarães Sá. En el volumen IX, titulado Rainhas-Consortes de D. Manuel I: Isabel de Castela, Maria de Castela e Leonor da Áustria, se encontrarán indicios de las infantas castellanas como reinas portuguesas.

${ }^{5}$ Sirva como ejemplo la obra fundamental: N. Salvador Miguel (2008).

${ }^{6} \mathrm{M}^{\mathrm{a}}$. I. del Val Valdivieso (2006), pp. 555-562.

${ }^{7}$ J. Luis Vives (1995), libro I, cap. 4, pp. 53-54. 
Sabemos que el maestro de la infanta Isabel fue, en sus primeros años, un humanista de la talla de Antonio Geraldini, al que relevó en el cargo el dominico fray Pedro de Ampudia; el de Juana fue fray Andrés de Miranda, el mismo que instruyó inicialmente a María; finalmente, María y Catalina compartieron como tutor a Alessandro Geraldini, todo ello según consta en las noticias de las Cuentas de Gonzalo de Baeza ${ }^{8}$.

También en la traducción anónima al castellano de la famosa obra el Carro de las donas, a cargo de Françesc Eiximenis (1542), se destacan los perfiles de las cuatro hijas de la reina Isabel, proponiéndolas como modelos de virtud, honor y religiosidad. De la infanta Isabel, por ejemplo, se alaban sus incipientes dotes de gobierno así como su profunda religiosidad:

\begin{abstract}
... fue dotada en los bienes de natura de excelentíssimo ingenio y grande saber: esto hera cosa muy cierta que, cuando sus padres tenían algún consejo arduo, siempre su consejo y parescer hera muy estimado de todos quantos allí estavan [...] fue quando donzella tan sancta y devota y tan sabia y tan perfecta que subió en todo grado de perfectión, de honestidad. Dotada en dones de gracia, en rezar e ayunos e limosnas y devotas contemplaciones y sentimientos de nuestro señor Jesu Christo?.
\end{abstract}

Otro punto fundamental a tratar dentro del armazón de mi tesis, verdadero pilar de la misma, será la literatura realizada en su honor o bien auspiciada por ellas en clara labor de mecenazgo. Por todo ello, aunque mi investigación se centra en la literatura castellana, atenderá a los escritos en otras lenguas, especialmente el latín, como ya he dicho anteriormente, pero también tendrá en el horizonte el italiano, el flamenco, el inglés y el portugués. Por otro lado, si bien mi objetivo para la tesis sea la literatura que se produce en vida de las infantas profundizando en los discursos políticos que suscitaron, es decir, la que comprende los siglos XV y XVI, mi futuro interés investigador se abrirá a analizar su imagen y proyección posterior en la literatura más allá de la Edad Media.

\title{
4. Algunos problemas: el caso de Juana
}

Esta última idea quizá sea la más atractiva de todas, pero no voy a negar que se muestra la más inabarcable y oceánica. Seguir los pasos de la literatura sobre las infantas, por caso, en el Siglo de Oro, me lleva a tratar con el ingenio de Calderón, en su obra La cisma de Inglaterra (1627), sobre el divorcio de Catalina de Aragón con Enrique VIII, tema que también trató el inglés William Shakespeare, en su

${ }^{8}$ G. de Baeza (1955), p. 132 y también en el artículo de A. de la Torre (1956), pp. 256-266.

${ }^{9}$ Apud J. L. Martín Rodríguez (2001), p. 101. 
Henry VIII or all is true $(1623)^{10}$. Más tarde, si tomamos la figura de Juana de Castilla como ejemplo de la proyección literaria de estas mujeres a lo largo de los siglos, el Romanticismo explotó sus múltiples matices como heroína romántica, principalmente, mujer marginada políticamente, reina sin corona y esposa definida como "Quijote del amor conyugal" . De este modo, apareció el estudio de Antonio Rodríguez Villa, titulado La Reina Doña Juana la Loca (1892), que propició un artículo-reseña de Emilia Pardo Bazán en su Nuevo Teatro Crítico ${ }^{12}$, en el que describía al personaje desde los tópicos románticos,

Juana la Loca sería la más conmovedora y sublime de las heroínas de Shakespeare si este semidiós literario no hubiese reservado su musa para narrar los infortunios (menos trágicos) de otra hija de los Reyes Católicos: Catalina de Aragón la repudiada [...] Pradilla en un lienzo, Tamayo en un drama, intentaron expresar la aterradora poesía de la lúgubre odisea de una demente de amor, en compañía de un muerto[...] Grandes artistas son de seguro Tamayo y Pradilla, pero el asunto sobrepuja su inspiración. Lo repito: sólo Shakespeare podría dar forma en las regiones del arte a Doña Juana la Loca $^{13}$.

Efectivamente, la figura de Juana se trató en todas las disciplinas artísticas y años atrás la habían llevado al lienzo artistas como Lorenzo Vallés con su Demencia de doña Juana de Castilla (1866), o el conocido Doña Juana la Loca de Francisco Pradilla (1877) ${ }^{14}$. También Manuel Tamayo y Baus con su Locura de amor (1855) o Ramón Franquelo ${ }^{15}$ habían escrito dramas sobre Juana. Pero, sin duda, es la última incursión teatral de Benito Pérez Galdós, Santa Juana de Castilla ${ }^{16}$, la que suscita más interés de entre todo este mélange de tópicos románticos. Estrenada el 8 de Mayo de 1918 en el teatro de la Princesa de Madrid y con Margarita Xirgu como actriz principal, la obra, definida por el propio autor como "poema dramático",

${ }^{10}$ Escrita en colaboración, posiblemente, con John Fletcher y estrenada en el Globe Theatre de Londres en 1613, la obra apareció manuscrita con diferentes títulos hasta su publicación en el conocido First Folio de 1623. Durante su estreno, un cañón explotó en el Globe provocando su derrumbe. Cfr. W. Shakespeare (2000), p. 941.

${ }^{11}$ Emilia Pardo Bazán (1892), p. 103.

12 Ibidem, pp. 67-105.

${ }^{13}$ Ibidem, p. 68.

${ }^{14}$ Ambos lienzos pueden ser contemplados en el Museo del Prado.

${ }^{15}$ En 1855, Manuel Tamayo y Baus estrena Locura de amor con notable éxito. En 1864 Ramón Franquelo estrena Doña Juana la Loca: drama histórico dividido en seis cuadros y escrito en verso, donde el tópico de Juana la Loca como personaje romántico y enajenada de amor es más que palpable.

${ }^{16}$ Hay edición moderna, de todo punto mejorable, de F. Rebollo Sánchez (2010). 
prescinde de los manidos tópicos tardorrománticos para adentrarse en un personaje que, en su tratamiento, encierra un bello espiritualismo cristiano no exento de un profundo simbolismo, así como una justa dignificación histórica del mismo. La acción tiene lugar en Tordesillas, en la Semana Santa de 1555. Juana de Castilla lleva cuarenta y seis años en este lugar, apartada del mundo, en el más completo olvido, a instancias de su padre, Fernando el Católico y más tarde de su hijo Carlos $\mathrm{V}$. La total desatención de la que fuera reina es relatada desde el inicio de la obra por dos criados de la misma, Mógica y Marisancha, que plantean un conflicto teatral dicotómico, por un lado la "supuesta" locura de la reina; por otro la "supuesta" herejía de Juana, lectora voraz de Erasmo. Nada se dice de su amor por Felipe el Hermoso, pues hábilmente Galdós elude tal interpretación.

El personaje de Juana le sirve a Galdós para exponer su ideología religiosa, una vez más y ahora de forma más simbólica y menos dogmática que en novelas anteriores como Doña Perfecta o Gloria. Todo ello se puede resumir en esta bella intervención de Juana:

Quiero el agua pura y limpia, como la que cae del cielo cuando lloran las nubes para fertilizar la tierra y purificar todas las cosas; quiero el agua traída por la divina esencia, licor no contaminado aún por las turbulencias de los ríos, que arrastran en su corriente todas las malicias, todas las miserias humanas. En esta idea se funda mi criterio religioso ${ }^{17}$.

Por esa época, también resulta sobresaliente la emotiva "Elegía a doña Juana la Loca" de Federico García Lorca $(1918)^{18}$, que vuelve a incidir en los tópicos románticos:
¿Tienes los ojos negros abiertos a la luz?
¿O se enredan serpientes a tus senos exhaustos?
¿Dónde fueron tus besos lanzados a los vientos?
¿Dónde fue la tristeza de tu amor desgraciado?
En el cofre de plomo, dentro de tu esqueleto, tendrás el corazón partido en mil pedazos ${ }^{19}$.

La literatura del siglo XX también se apropió del personaje de Juana dotándolo de una nueva vuelta de tuerca. Ramón Gómez de la Serna le dedicó su Doña Juana la Loca (y otras): Seis novelas superhistóricas (1949), una personal mirada sobre el personaje lleno de luz y poesía. Más tarde, Ana Diosdado en Los comuneros (1974)

\footnotetext{
${ }^{17}$ Galdós (2010), p. 73.

${ }^{18}$ F. García Lorca (1996), pp. 73-75.

${ }^{19}$ Ibidem, p. 74.
} 
y José Martín Recuerda en El engañao (1976) son un buen ejemplo de autores a los que el personaje de Juana les ha servido de pretexto para crear un texto que explora la historia en un ejercicio de revisionismo histórico en un momento candente en el terreno político de España.

Más aún, en los últimos años, Juana la Loca ha sido objeto de novelas superventas (El pergamino de la seducción de Gioconda Belli, 2004, cuenta con numerosas ediciones) así como exitosas películas (Juana la Loca de Vicente Aranda, 2001), óperas (Rage d'amours de Rob Zuidam, 2003) y coreografías como la llevada a las tablas por Sara Baras en su Juana la Loca: vivir por amor (2002).

De modo que, a la vista de estas consideraciones sobre la figura de Juana, como en el juego de las muñecas rusas, mi tesis englobaría en sí misma varias tesis más, pues también ha de tenerse en cuenta que el mito ha atravesado fronteras y ha llegado a Francia, Inglaterra y, más aún, en viaje transatlántico, a la literatura hispanoamericana, que ha dedicado novelas y obras de teatro al respecto ${ }^{20}$. Por lo tanto, estudiar estos y otros asuntos parece interesante y muy necesario, a la vista de ciertos silencios bibliográficos en determinados aspectos, pero es justo reconocer que dicha labor desbordaría los límites razonables de la tesis, volviéndose inmanejable y oceánica.

Por ello, en un principio, la perspectiva histórica y literaria de las cuatro hijas de los Reyes Católicos, tan atrayente por otra parte, no será un aspecto incluido en mi tesis pero, lejos de desanimarme u olvidarlo, será un tema de sumo interés que me ayudará a desarrollar mi labor investigadora ocupándome de ello en futuros y diversos artículos, congresos o seminarios de investigación.

\section{Los inicios: el caso de Isabel}

A modo de ejemplo, y como ya hemos indicado con Juana, tomemos ahora la figura de la primogénita de los Reyes Católicos, Isabel, para ver cómo se desarrolla su historia y literatura en mi tesis ${ }^{21}$. A ella estoy dedicando los inicios de mi investigación doctoral, que paso a explicar. En primer lugar, he de realizar una pequeña biografía, es decir, trazar las coordenadas vitales y políticas donde insertar al personaje. Así pues, la infanta vino al mundo en Dueñas, Palencia, el 2 de octubre de 1470, en plena guerra civil castellana por los derechos sucesorios al trono, a la que seguiría la guerra peninsular contra Portugal. Parece importante resaltar a este respecto que los hechos políticos condicionarán y marcarán la vida de estas mujeres,

\footnotetext{
${ }^{20}$ Enumerar los títulos existentes sobrepasa con creces el objetivo de este artículo; por ello, para un buen repaso a la figura de Juana la Loca en el tiempo y el espacio, véase la monografía de M. A. Gómez, S. Juan-Navarro y P. Zatlin (2008), especialmente el Appendix II, titulado "Juana as a Palimpsest".

${ }^{21}$ En estos inicios, reconozco la deuda con el inventario de textos realizado por J. Sanz Hermida en el artículo citado.
} 
pues Isabel se casaría con el príncipe Alfonso de Portugal, como consecuencia de los acuerdos de paz entre Castilla y el país vecino.

Tras años de tercerías en Portugal, idas y venidas matrimoniales, la boda con el heredero portugués tuvo lugar en Sevilla, el 19 de abril de 1490, y se celebró con importantes fiestas públicas que incluyeron juegos de cañas, justas, toros y magníficos momos, encargados por el príncipe don Juan a su hermana, como años antes hiciera la Reina Católica con los momos encargados a Gómez Manrique para celebrar el cumpleaños de su hermano Alfonso. Pero también la infanta Juana encargó unos momos que costaron cerca de 44.068 maravedíes, con gran adorno de «plata de copela batida e dorada» y tiras de ropa. Sin embargo, los más espectaculares y costosos fueron los encargados por el príncipe, donde debieron de intervenir unos quince o veinte pajes ${ }^{22}$ con todo el lujo en su vestuario adornado con las más vistosas telas. Sin duda, lo más sorprendente debió de ser el "escenario" para los dichos momos, pues esta arquitectura efímera, definida en las Cuentas de Baeza como «hedificio», contó con un castillo revestido de plata y se vio aderezado con la presencia de figuras de leones y la intervención de pajes y algunos salvajes, quizá para representar algún tipo de batalla cortesana entre estos y los pajes del príncipe ${ }^{23}$.

En este contexto de celebración debe insertarse la composición que Antonio de Nebrija dedica a los novios con motivo del enlace, me refiero al poema que se conoce con el título general de Epithalamium, y que, según el propio autor, «recitó Antonio de Nebrija, quien estuvo presente en estos días festivos». El poema consta de cerca de cien versos en latín, con su correspondiente comentario humanístico en glosa, que hizo de las bodas su circunstancia, pues la loa matrimonial se convierte en mero pretexto para ensalzar la gloria de los Reyes Católicos. Actualmente me estoy ocupando del poema para elaborar su edición moderna además de su traducción al castellano pues, pese a las muchas referencias indirectas, aún carecemos de ella. Gracias a este difícil, pero maravilloso trabajo de edición, mi investigación se enriquece con lecciones de historia, la necesaria para trazar la vida y hechos políticos de la infanta; literatura, enraizada en el humanismo castellano y con la figura de Nebrija como real vate; filología, desde el difícil latín del Nebrisense al castellano actual y, por último, bibliografía material y tipobibliografía, al describir las distintas ediciones donde se inserta el poema, toda una aventura bibliográfica que va desde los incunables hasta las ediciones tuteladas por los herederos de Nebrija ${ }^{24}$. Así se puede apreciar la necesaria y útil interdisciplinariedad a la que me vengo refiriendo.

\footnotetext{
${ }^{22}$ Así se deduce de las Cuentas, según las cuales se encargaron dieciséis sombreros y diecinueve pares de calzas, ob. cit., I, p. 339. Cfr. Á. Fernández de Córdova Miralles (2002), p. 267.

${ }^{23}$ Cuentas, I, p. 340.

${ }^{24}$ Dicha edición, que verá la luz muy pronto y que recogerá buena parte de mis investigaciones hasta la fecha sobre la infanta Isabel, tiene como origen mi Trabajo Final de Máster
} 
A su llegada a Portugal, la ya princesa Isabel fue agasajada con numerosas "fiestas y alegrías", las acostumbradas para celebrar el reciente matrimonio: una Oratio latina de Cataldo Parísio Sículo, leída en Évora ${ }^{25}$, justas, torneos y banquetes que incluían «entremeses y representaçoes», como el famoso carro que entró al salón lleno de terneros y vacas asadas con cuernos y patas dorados. También se representaron «ricos momos» que se suelen identificar con la historia de Amadís y Esplandián ${ }^{26}$. Una vez más, la interdisciplinaridad se hace patente al considerar los numerosos romances y poemas escritos en portugués sobre este tema, como por ejemplo el de Luis Anríquez, ("¡Oh pueblo de Portugal / lhorad la triste cayda”), quien rememora dichos días de celebración:
A quien eyçelentes bodas,
fyestas, justas tam gozosas
y creçidas,
a las cuales hyvan todas
las jentes tan desseosas
de sus vidas.
¡Ricas ropas y colhares,
brocados, grandes baxilhas
y pedraria,
quanto gozo en los luguares,
em las çidades y vilhas
se azia! ${ }^{27}$

Pero, lamentablemente, en la noche del doce de julio de 1491 muere el príncipe Alfonso tras caer de un caballo, circunstancia luctuosa que favorece una fértil literatura consolatoria. Poemas, romances y tratados introducen la voz femenina de la infanta Isabel, ya que su lamento fue cantado por los cronistas portugueses y los humanistas castellanos, pues «su manjar hera lágrimas de día y de noche». Me refiero al anónimo poema "Hablando estava la reina en su palacio real / con la infanta de Castilla, princessa de Portugal..."; al escrito por don Juan Manuel, "A lagrimas tristes, a tristes cuydados / a graves angustias, a mortal dolor"; o el extenso poema

en Literatura Española (Universidad Complutense de Madrid) titulado "Et iungat vesper amantes", un Epithalamium nebrisense en honor de la primogénita de los Reyes Católicos, la infanta Isabel de Castilla. Edición y estudio.

${ }^{25}$ Cataldo Parísio Sículo también escribe otra oración para la infanta María a la llegada al reino portugués que fue recitada en Santarém.

${ }^{26}$ Á. Fernández de Córdova Miralles (2002), p. 267-268.

${ }^{27}$ G. de Resende (1973), I, p. 318. 
anteriormente citado de Luis Anríquez, por destacar sólo algunos, como la Égloga V de Juan del Encina sobre la muerte de Danes, trasunto del príncipe Alfonso.

En mi tesis trataré de sistematizar los poemas dedicados a Isabel y de analizar la proyección literaria de la figura de la infanta, baste ahora como ejemplo la anterior composición de don Juan Manuel a la muerte del príncipe don Alfonso. En ella, se describe cómo afecta la muerte del heredero a su familia más próxima, a su pueblo, sus padres y cómo no, a su "cara mujer":
$\mathrm{O}$ alta Prinçesa, la mas virtuosa que oyeron ny vieron jamas los umanos del vuestro marydo syn fyn deseosa, syn fyn deseada de los lusytanos. Nefanda Furtuna y casos mundanos por nuestros pecados an delyberado de los vuestros braços ser arrebatado y puesto de donde le coman los gusanos.
$¡ O$ cuan desymyles fueron y son la vuestra venyda y vuestra tornada, la una tan prospera y tan sublymada, la otra $\tan$ lhena de tribulaçion!
De marmor por çierto es la condiçion que pudo sofrir ver como partistes se vydo y se nyembra de como vynistes de tan poco tiempo tan gran mutaçion ${ }^{28}$.

Sin duda, el año escaso que transcurrió entre la boda y la muerte de Alfonso propició las comparaciones entre la alegría y el dolor que también se observan en el poema de Anríquez, quien introduce un extenso planto para dar voz en primera persona a la infanta Isabel:
$¡ O$ amor de my querer, querido del corazón mas que my vida, començo de my plaçer, començo de my passion desmedida!
$¡ \mathrm{O}$ fym de todo my bien venero de my tristura sym compas,

${ }^{28}$ G. de Resende (1973), I, p. 168. 
sola yo, dyram de quien se partio boena ventura por jamas!

¡Yo soy la triste veuda, cuberta de mil tresturas, sym abrigo, de todo my bien desnuda y muy lhena d'amarguras, sym amiguo! $!^{29}$

Para paliar esa "tristura", Alonso Ortiz, canónigo toledano, le dedica a la princesa de Portugal un interesante Tratado consolatorio a la princesa de Portugal (1493), que va precedido de una carta a la reina Isabel, excusándose de haberlo escrito en romance, «porque si nos vencieren en las lenguas peregrinas, los extraños callarán en la nuestra, que no es entre los doctos de pequeña excelencia». En efecto, se trata del texto consolatorio en romance más extenso de los conservados: en veintisiete capítulos, Ortiz desgrana todos los tópicos de la literatura consolatoria, la justicia divina, la fe inquebrantable más el poder de la razón y el discreto juicio. Dicho tratado se presta, en el transcurso de mi investigación, a ser objeto de una moderna edición filológica ${ }^{30}$.

La muerte del heredero de Portugal, en palabras de Luis Suárez Fernández, "había significado un quebranto muy serio en la política de los Reyes Católicos: para ellos disponer de un vínculo de parentesco con aquel reino era una necesidad $^{31, "}$, por lo que los Reyes Católicos se apresuraron a concertar una segunda alianza con el país vecino, enlace que Pedro Mártir de Anglería se encargó de constatar en sus Epístolas: Isabel se casaría con Manuel de Portugal, conocido para la historia como el Afortunado. De esta unión nació el tan ansiado heredero al trono castellano, Miguel de la Paz, pero en el alumbramiento, acaecido en Zaragoza, la princesa Isabel murió de sobreparto (1498), lo que propició más literatura consolatoria en el entorno de los Reyes Católicos, esta vez sobre la primogénita. Así, la Carta de Íñigo de Mendoza al Rey Católico, el Panegírico de Diego Guillén de Ávila o las coplas que Francisco de Ávila dedica al principito Miguel y a Isabel en su Vergel de discretos.

\footnotetext{
${ }^{29}$ G. de Resende (1973), I, p. 320.

${ }^{30} \mathrm{La}$ intención es patente al comprobar que sólo existe una edición parcial de la obra, es decir, únicamente se tratan los capítulos XI, XII y XIII a cargo de A. M. Arancón (1980), pp. 243-261.

${ }^{31}$ L. Suárez Fernández (1990), p. 109.
} 


\section{Conclusión}

En definitiva, estos inicios de mi tesis doctoral, que aquí han quedado presentados, no son más que el firme deseo y determinación de llevar al papel una investigación que, sabiamente dirigida más el necesario consejo de los expertos y la madurez de unos cuantos años dedicados a su labor, resultará del trabajo minucioso y paciente. La necesidad de realizar dicho trabajo es más que evidente al apreciar las lagunas que han quedado expuestas en el repaso que aquí se ha realizado.

Este reto filológico que aquí se plantea, con sus flaquezas y aciertos, no ha de ser entendido como una meta difícil y costosa de alcanzar, sino como un atractivo punto de partida para los futuros años de aprendizaje acerca de la literatura en torno a las hijas de los Reyes Católicos.

\section{Obras citadas}

Antología de humanistas españoles, ed. de Ana M. Arancón, Madrid, Editora Nacional, 1980.

BAEzA, Gonzalo (de): Cuentas de Gonzalo de Baeza, tesorero de Isabel la Católi$c a$, ed. de Antonio de la Torre y E. A. de la Torre, Madrid, Patronato Marcelino Menéndez Pelayo, 1955, 2 vols.

CORDEIRO DE SOUSA, José Manuel: "Apuntes sobre la vida y muerte de la reina doña María, hija de los Reyes Católicos", Revista de Archivos, Bibliotecas y Museos, LVII (1951), pp. 657-696.

"Notas acerca de la boda de Isabel de Castilla con el príncipe don Alfonso de Portugal": Revista de Archivos, Bibliotecas y Museos, LX (1954), pp. 33-51.

FERNÁNDEZ DE CóRDOVA MIRALLES, Álvaro: La corte de Isabel I, ritos y ceremonias de una reina (1974-1504), Madrid, Dykinson, 2002.

García LORCA, Federico: Obras completas (I), Poesía, ed. de Miguel GarcíaPosada, Barcelona, Círculo de Lectores, Galaxia Gutenberg, 1996.

Gómez, María A.; JuAn-NAVArRo, Santiago y Zatlin, Phyllis (eds.): Juana of Castile. History and Myth of the Mad Queen, Lewisburg, Bucknell University Press, 2008.

GonZÁlez Rolán, Tomás; Baños Baños, José Miguel y SAQuero SuÁREZ-

SOMONTE, Pilar: El humanismo cristiano en la corte de los Reyes Católicos: las "Consolatorias" latinas a la muerte del príncipe Juan de Diego de Muros, Bernandino López de Carvajal-García de Bovadilla, Diego Ramírez de Villaescusa y Alfonso Ortiz, Madrid, Ediciones Clásicas, 2005.

Llanos y TORRIGLia, Félix (de): Isabel de Castilla, Reina de Portugal, Madrid, Ediciones Historia, (s. a.).

Cuatro reinas españolas en la epopeya portuguesa de los descubrimientos, Madrid, Instituto de España, 1944. 
1946.

MARTÍN RODRÍGUEZ, José Luis: Isabel la Católica: sus hijas y las damas de la corte, modelos de doncellas, casadas y viudas en el "Carro de las donas", 1542, Ávila, Diputación Provincial y Ayuntamiento, 2001.

PARDO BAZÁN, Emilia: "Un drama psicológico en la historia: Juana la Loca, según los últimos documentos", Nuevo Teatro Crítico, año II, número 14 (febrero de 1892), pp. 67-105. Accesible en línea a partir de www.cervantesvirtual.com.

PÉREZ GALDós, Benito: Santa Juana de Castilla, ed. de Félix Rebollo Sánchez, Madrid, Fragua, 2010.

PÉREZ PRIEGO, Miguel Ángel: "Historia y literatura en torno al príncipe don Juan. La Representación sobre el poder del amor de Juan del Encina", en Historias y Ficciones: coloquios sobre la literatura del siglo $X V$, eds. R. Beltrán, J. L. Canet y J. L. Sirera, Valencia, Universitat, 1992, pp. 227-249.

El príncipe don Juan, heredero de los Reyes Católicos y la literatura de su época [Lección inaugural del Curso 1997-1998, UNED], Madrid, UNED, 1997.

RESENDE, García (de), Cancioneiro geral, ed. de Álvaro J. da Costa Pimpão y Aida Fernanda Dias, Coimbra, Centro de Estudos Romãnicos, 1973.

SAlVADOR Miguel, Nicasio: Isabel la Católica. Educación, mecenazgo y entorno literario, Alcalá de Henares, Instituto de Estudios Cervantinos, 2008.

SANZ HERMIDA, Jacobo y AlCALÁ GALVE, Ángel: Vida y muerte del príncipe don Juan: historia y literatura, Valladolid, Junta de Castilla y León, Consejería de Educación y Cultura, 1999.

"A vos Diana primera leona: literatura para la princesa y reina de Portugal, la infanta Isabel de Castilla", Península. Revista de Estudios Ibéricos, 1 (2004), pp. 379-394.

SHAKESPEARE, William: Dramas históricos, trad. de Luis Astrana Marín, Madrid, Espasa, 2000.

SuÁREZ FERNÁNDEZ, Luis: Los Reyes Católicos, el camino hacia Europa, Madrid, Rialp, 1990.

TORRE, Antonio (de la): "Maestros de los hijos de los Reyes Católicos", Hispania, 63 (1956), pp. 256-266.

VAL VALDIVIESO, M ${ }^{\mathrm{a}}$ Isabel (del): “Isabel la Católica y la educación”, Aragón en la Edad Media, 19 (2006), pp. 555-562.

VIVES, Juan Luis: Instrucción de la mujer cristiana, trad. de Elizabeth Teresa Howe, Madrid, Fundación Universitaria Española, Universidad Pontificia de Salamanca, Madrid, 1995.

WHINNOM, Keith: "Spanish Literary Historiography: three Forms of Distortion”, en Medieval and Renaissance Spanish Literature. Selected Essays, eds. Alan Deyermond, W. F. Hunter y Joseph Snow, University of Exeter Press, 1994, pp. 96113. 